
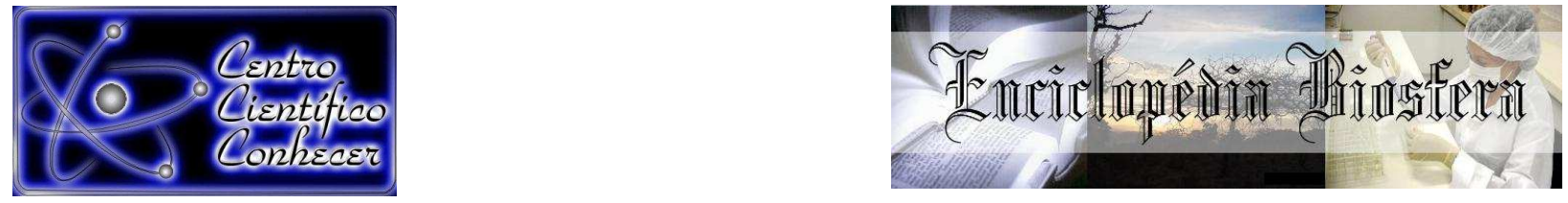

\title{
ANÁLISE DA DEGRADAÇÃO AMBIENTAL DA MATA CILIAR DA REPRESA DA UNIVERSIDADE FEDERAL DO TOCANTINS, GURUPI-TO
}

Lucas Pazoliny Barros Benicío1, Patrícia Aparecida Souza², Bianca Pietsch Cunha Bendito $^{3}$, André Ferreira dos Santos ${ }^{4}$, Priscila Bezerra de Souza ${ }^{5}$

\footnotetext{
${ }^{1}$ Academico do Curso de Engenharia Florestal pela Universidade Federal do Tocantins, Gurupi - Brasil.

${ }^{2}$ Profa . Drª . do programa de pós graduação em Ciência Florestais e Ambientais, Universidade Federal do Tocantins, Gurupi - Brasil.

${ }^{3}$ Mestranda em Ciência Florestais e Ambientais pela Universidade Federal do Tocantins, Gurupi - Brasil. (biancapcb.engamb@gmail.com)

${ }^{4}$ Prof. Dr. do programa de pós graduação em Ciência Florestais e Ambientais, Universidade Federal do Tocantins, Gurupi - Brasil.

${ }^{5}$ Profa . Drª . do programa de pós graduação em Ciência Florestais e Ambientais, Universidade Federal do Tocantins, Gurupi - Brasil.
}

Recebido em: 02/10/2017 - Aprovado em: 21/11/2017 - Publicado em: 05/12/2017 DOI: 10.18677/EnciBio_2017B5

\begin{abstract}
RESUMO
A vegetação ciliar desempenha importante função ambiental, mais especificamente na manutenção da qualidade de água, na estabilidade dos solos das áreas marginais e na regularização do regime hídrico. Essas formações florestais são consideradas áreas de proteção permanente (APP) pela Lei 1265/2012 que instituiu o Código Florestal Brasileiro. No município de Gurupi-TO nas localidades da Universidade Federal do Tocantins, existe uma área de mata ciliar, às margens da represa, que está degradada e necessita ser recuperada. Foi realizado então um diagnóstico ambiental, "Check-list", matriz de interação e rede de interação e foi observado que os impactos mais significativos foram perda da biodiversidade e alteração qualitativa da água. Entre as medidas necessárias para mitigação dos danos estão: a supressão da vegetação exótica, manejo do solo e revegetação da área.
\end{abstract}

PALAVRAS-CHAVE: Área degradada, impacto ambiental, represa.

\section{ANALYSIS OF THE ENVIRONMENTAL DEGRADATION OF RIPARIAN FOREST DAM FEDERAL UNIVERSITY OF TOCANTINS, GURUPI-TO}

\begin{abstract}
Riparian forests play an important environmental role, mainly in the maintenance of water quality, in the soil stability of marginal areas, and in the regularization of the water regime. The riparian forests are considered permanent protection areas (APP) by Law 1265/2012 that established the Brazilian Forest Code. In the municipality of Gurupi-TO, in the localities of the Federal University of Tocantins, a degraded area of
\end{abstract}


ciliary forest exists along the banks of the dam, an it needs to be recovered. An environmental diagnosis, a "Check-list", an interaction matrix and an interaction network were carried out and it was observed that the most significant impacts were loss of biodiversity and altteration of water quality. Among the measures needed to mitigate the damages are: removal of exotic vegetation, management of the soil and revegetation of the area.

KEYWORDS: Degraded area, environmental impacto, dam.

\section{INTRODUÇÃO}

Existe há mais de um século no Brasil a preocupação com a reparação de problemas ambientais causados pelo homem no meio ambiente. Contudo, só na década de 1980, a partir do desenvolvimento da Ecologia da Restauração como ciência, que o termo Restauração Ecológica passou a ser claramente definido e a partir de então utilizado mundialmente (FRANCO, 2013).

Neste contexto, uma área que vem merecendo destaque é a das matas ciliares, regiões de grande importância ambiental, mas vêm sendo degradadas em todo Brasil. As matas ciliares, localizadas às margens de cursos de água (rios, lagos, nascentes, etc), são formações florestais que exercem importante função na estabilidade dos solos das áreas marginais, na regularização do regime hídrico e na manutenção qualitativa de água. Além disso, essas formações vegetais facilitam o deslocamento da fauna e o fluxo gênico entre as populações de espécies animais e vegetais, pois funcionam como corredores ecológicos que ligam fragmentos florestais (ROCHA et al., 2014).

Entre os inúmeros fatores que têm contribuído para a degradação dessas áreas, destacam-se os desmatamentos e os incêndios. Segundo Paula et al. (2012), construções de barramentos também vêm gerando impactos em ambientes ciliares, pois causam diversas mudanças no meio físico e nas relações da fauna e da flora, refletindo negativamente no ecossistema dos locais onde são instalados.

Estas faixas de vegetação que margeiam os corpos hídricos foram classificadas no Código Florestal Brasileiro desde 1965 como área de proteção permanente (APP), tornando-as protegidas por lei (MARTINS, 2013). Assim, toda a vegetação natural, existente ao longo das margens dos rios e ao redor de nascentes e de reservatórios, deve ser preservada e recuperada (AMBIENTE BRASIL, 2015).

A restauração destas áreas pode ser realizada por meio da regeneração natural, quando o local possui resiliência, ou seja, presença de propágulos originais (parte vegetativa e bancos de sementes no solo), condições edafoclimáticas, entre outras características. Todavia, em situação onde a área não apresenta resiliência, a restauração deve ser realizada através de interferência antrópica direta: plantios de mudas, semeadura direta ou partes vegetativas (IBAM, 2015).

Para que a recuperação dessas áreas ser eficaz, é necessário fazer um diagnóstico ambiental da situação em que a área se encontra, com intuído de caracterizar os impactos existentes, para escolher a metodologia de recuperação mais viável ambiental e economicamente e que conduza a resultados satisfatórios. Logo, estudos sobre técnicas de diagnóstico ambiental são indispensáveis a fim de obter e aperfeiçoar metodologias de análise de impactos, que resultem na melhor escolha de recuperação para a área. Portanto, este estudo teve como objetivo diagnosticar os impactos na mata ciliar da represa da Universidade Federal do Tocantins e, através dos resultados, propor medidas mitigatórias. 


\section{MATERIAL E MÉTODOS}

\section{Área de estudo}

O trabalho foi realizado no Estado do Tocantins, no município de Gurupi, nas localidades do campus da Universidade Federal do Tocantins (UFT), a área de estudo está situada às margens da represa da Universidade, sob as coordenadas UTM $11^{\circ} 44^{\prime} 32,5$ S" e $49^{\circ} 02^{\prime} 59,6^{\prime \prime}$ W (Figura 01). O clima da região é úmido com moderada deficiência hídrica no inverno, precipitação média anual de $1550 \mathrm{~mm}$ e temperatura do ar média anual de $27,5^{\circ} \mathrm{C}$ (SEPLAN, 2012).

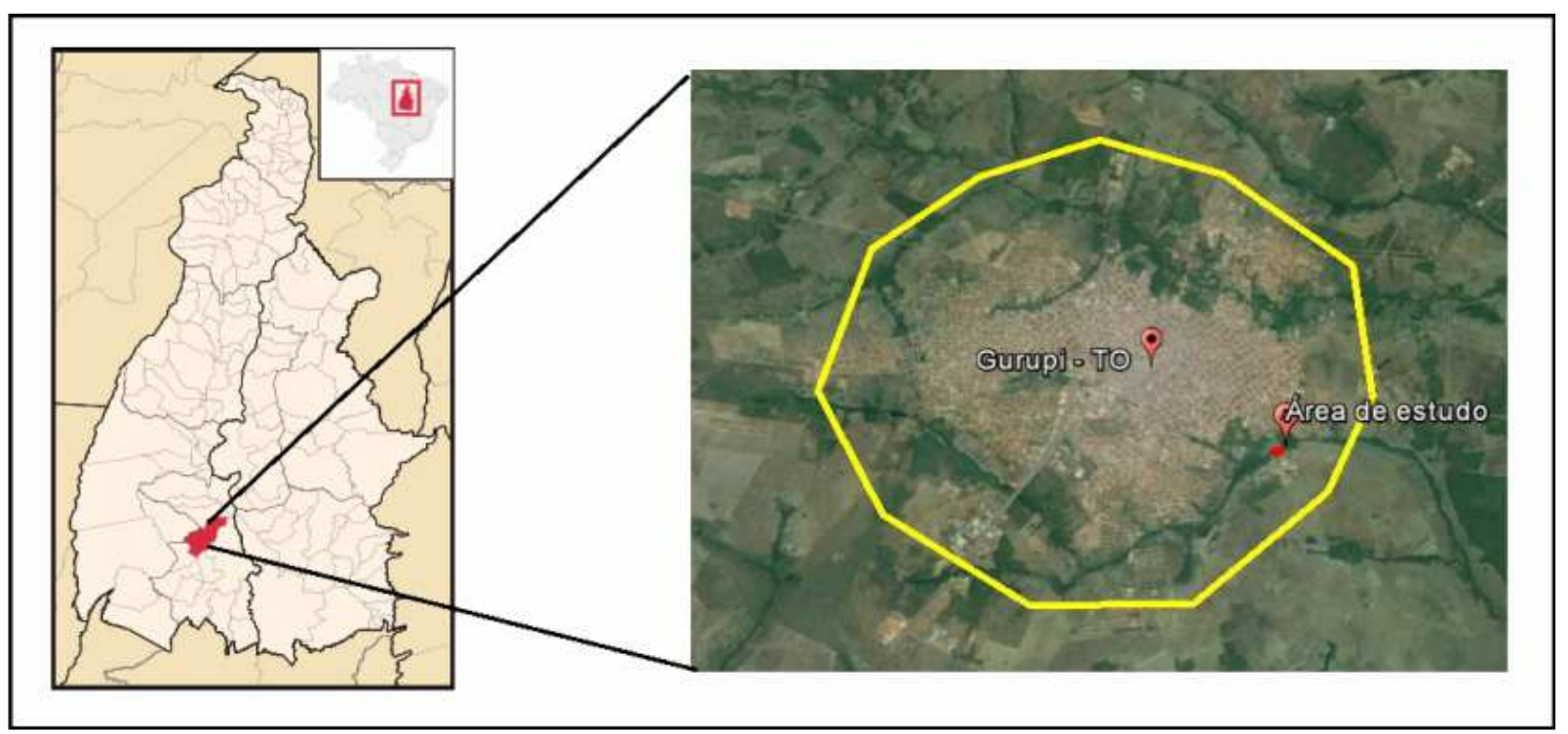

FIGURA 1: Localização da área de estudo. Fonte: Google imagens, Google Earth.

A represa foi construída com o barramento do córrego Água Franca no ano 2000. O corpo hídrico faz parte da Bacia do Rio Santo Antônio, incluída no Sistema Hidrográfico do Rio Tocantins. A vegetação é pertencente ao domínio Cerrado.

Inicialmente o rio Santo Antônio possuía a largura de $30 \mathrm{~m}$ e com o barramento passou a ter em torno de 130 metros de largura, 3 ha. Segundo a Lei no 12.651, de 25 de maio de 2012, que instituiu o Código Florestal brasileiro, a largura da faixa de mata ciliar a ser preservada está relacionada com a largura do curso d'água. Logo, para reservatórios em zona rural com área menor do que 20 há, como o corpo hídrico em estudo, a faixa deveria ser de 50 metros ao redor do espelho d'agua (BRASIL, 2012). 


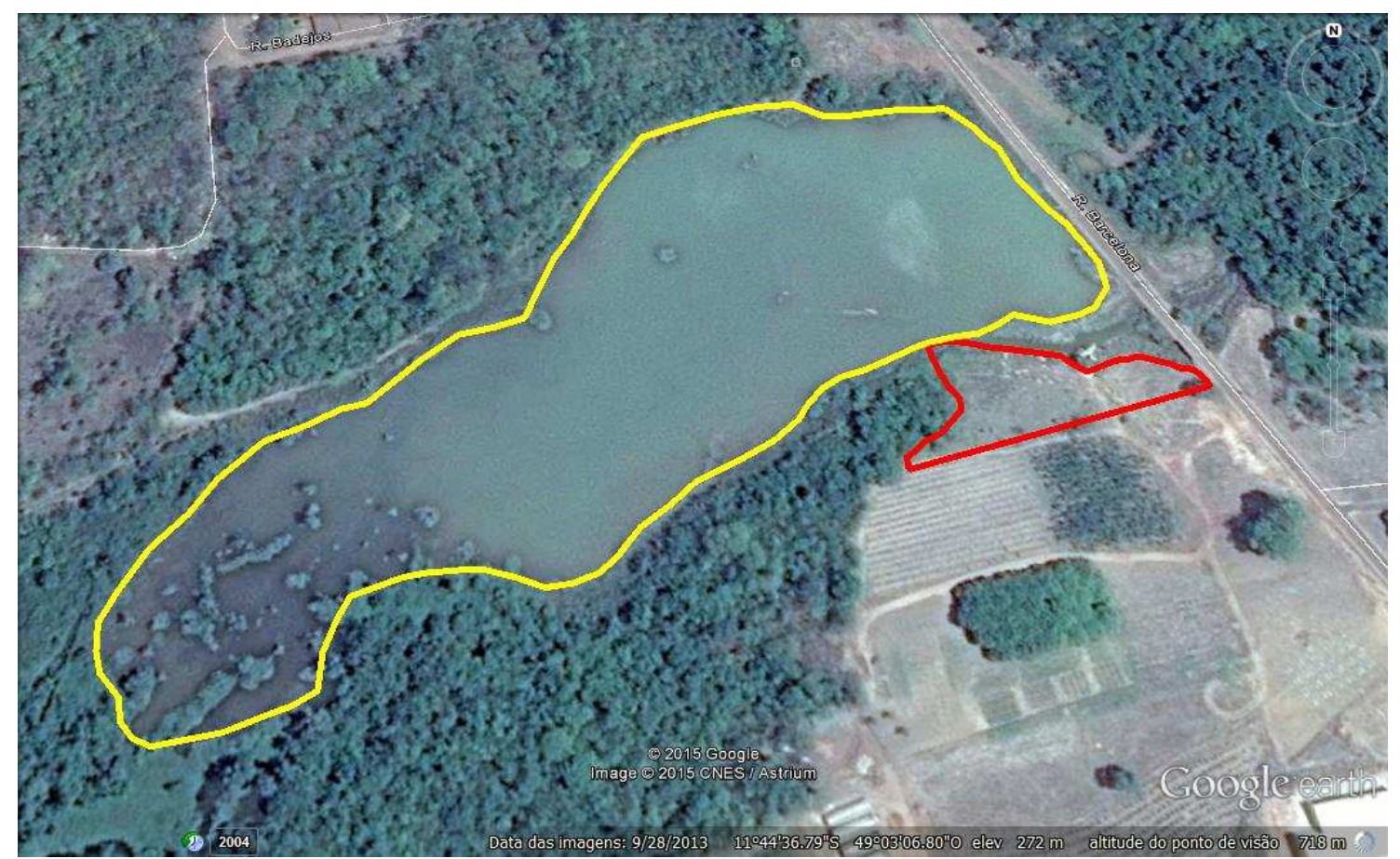

FIGURA 2: Área a ser recuperada (vermelho), em relação à represa (amarelo).

Fonte: Google Earth

\section{Metodologia}

Realizou-se visita a área durante o mês de novembro de 2015, com o objetivo de realizar diagnóstico ambiental da área, foram verificadas ações degradantes na área resultando em impactos ambientais. Foram feitos registro fotográfico e levantamento de dados pertinentes à caracterização da área.

A listagem das ações degradantes e dos impactos ambientais visualizados na área foi feita segundo a metodologia de "Check-list", na modalidade descritiva, citada por Sánchez (2008), que se baseia na identificação, na listagem dos danos ambientais referente aos meios abiótico, biótico e socioeconômico e descrição de como estes foram observados.

Com base no "check-list", realizou-se uma rede de interação dos impactos, materializada em fluxograma, que possibilita reconhecer impactos diretos e indiretos, através de uma sucessão de impactos ambientais decorrentes de cada ação impactante (CREMONEZ et al., 2014).

Posteriormente foi feita a qualificação e a quantificação dos impactos listados pelo "check-list", pelo método da matriz Leopold, et al. (1971) adaptava por Sanchez (2008), em cada impacto e analisando de acordo com seus efeitos nos meios abiótico, biótico e socioeconômico. Os critérios utilizados para qualificação foram os estabelecidos pela Resolução CONAMA nº 001/86: Ordem (Direto ou indireto), Plástica (Reversível ou Irreversível), Valor (Positivo ou Negativo), Dinâmica (Temporário, Permanente ou Cíclico), Tempo (Imediato, Curto Prazo ou Longo Prazo) e Espaço (Local, Regional ou Nacional) (BRASIL, 1986).

Os parâmetros escolhidos para análise quantitativa foram magnitude e importância (Quadro 1). A importância refere-se ao grau de influência que o impacto tem sobre a qualidade ambiental local, que pode ser importante, muito importante, não importante e desprezível. A magnitude refere-se à intensidade do impacto em um específico fator ambiental, que pode ser pequeno, médio e grande (MARTINS, 2013). 
QUADRO 1: Parâmetros quantitativos usados para avaliação dos impactos ambientais diagnosticados.

\begin{tabular}{|cc|cc|}
\hline IMPORTANCIA & \multicolumn{3}{c|}{ MAGNITUDE } \\
\hline Importante & $>$ & Não existe & 0 \\
\hline Muito importante & $>$ & Probabilidade de ocorrência & $\mathbf{1 > =} \mathbf{x}<\mathbf{3}$ \\
\hline Não importante & $<$ & Média magnitude & $\mathbf{3}>\mathbf{x}<\mathbf{5}$ \\
\hline Desprezível & $<$ & Alta magnitude & $\mathbf{5}>\mathbf{x}<\mathbf{7}$ \\
\hline
\end{tabular}

Fonte: Sanchez (2008)

\section{RESULTADOS E DISCUSSÃO}

Em concordância com as dimensões da represa e com as disposições da lei 1265 de 2012 consultada, que instituiu o Código Florestal Brasileiro (BRASIL, 2012), a área de mata ciliar da área de estudo deve ser de 50 metros ao redor do espelho d'agua, para que sejam restaurados os serviços ecossistêmicos prestado por essas áreas marginais. Na Figura 2, observa-se a área que deve ser recuperada.

Através da metodologia de "Check-list" foram encontrados os seguintes aspectos ambientais:

- Desmatamento;

- Plantas exóticas;

- $\quad$ Processo de assoreamento;

- Erosão acelerada.

$\mathrm{Na}$ área de estudo foi observado que boa parte do solo estava descoberto devido a retirada da vegetação (Figura 3 ). O desmatamento tem muitas consequências negativas para o meio biótico e abiótico (solo, a água, a fauna, flora e etc). Com a supressão da proteção natural fornecida pela vegetação, o solo fica exposto e os processos erosivos são acelerados, gerando entre outras consequências à diminuição da serapilheira, perda de umidade e nutrientes, morte de micro-organismos do solo, desestruturação, compactação do solo e redução da fertilidade (NERES et al., 2015). 


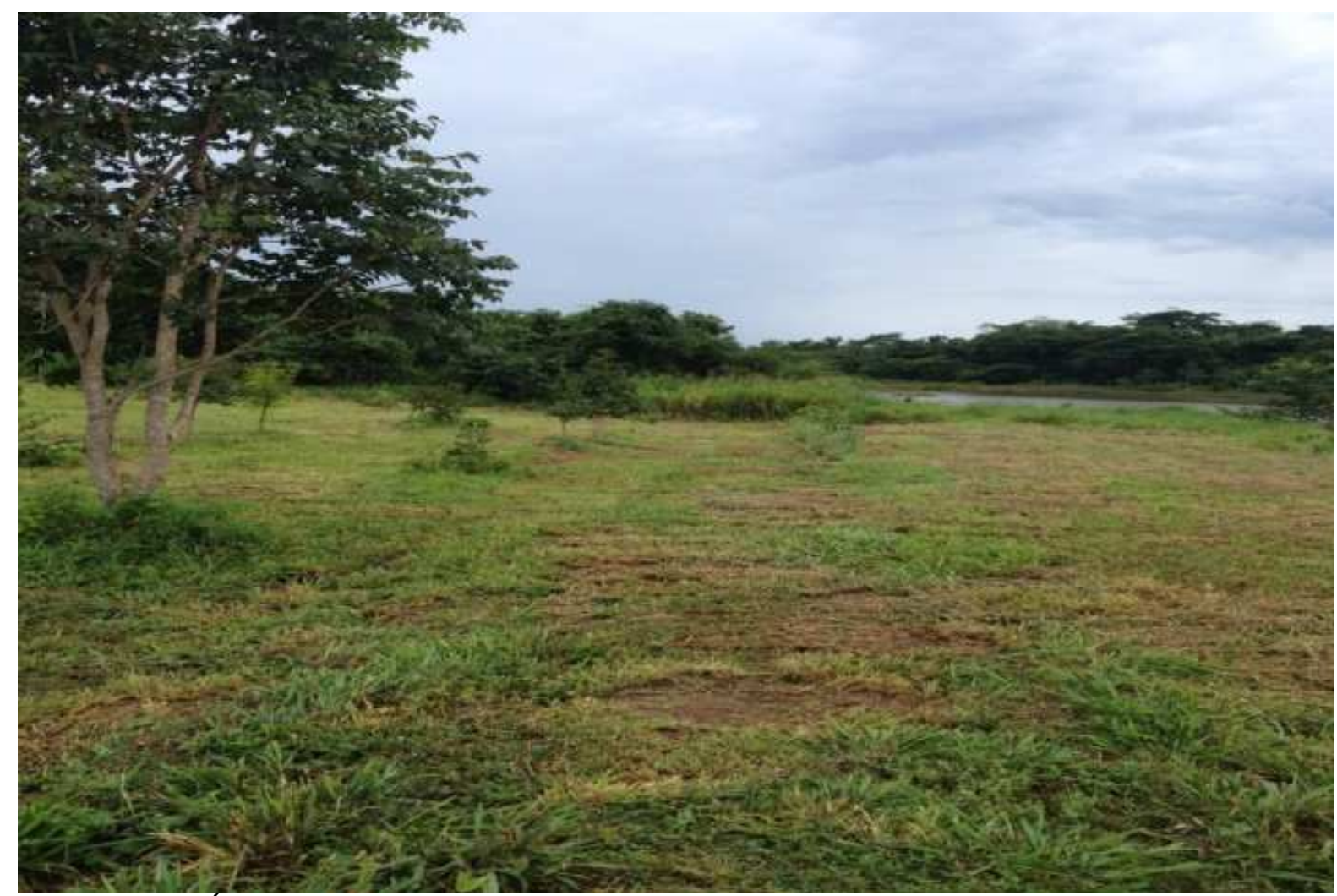

FIGURA 3: Área com escassa vegetação nativa resultante do desmatamento. Fonte: Autores

$\mathrm{Na}$ área de estudo foram observados acelerados processos erosivos, ocasionados pela supressão da vegetação nativa, que expôs o solo à ação de agentes erosivos. Além disso, a circulação de máquinas agrícolas, utilizadas na universidade, contribuíram para esse aceleramento causando compactação do solo, o que dificulta o restabelecimento da vegetação nativa. Dessa maneira, os processos de condução e deslocamento de elementos do solo (partículas sólidas, constituintes orgânicos e inorgânicos) são favorecidos e ocorre a lixiviação desses materiais até os corpos hídricos próximos, o que causa assoreamento dos sistemas aquáticos (SARl et al., 2013).

Foi diagnosticado no local o processo de assoreamento da água da represa, pois havia presença de sólidos suspensos em abundância na margem e uma elevação na turbidez (diminuição da transparência). Segundo Araújo et al. (2010) a antropização acelera os processos naturais de desgaste e perda do solo. Os modelos de uso da terra, os desmatamentos, as queimadas, o trânsito de máquinas agrícolas, a ausência de manejo agrícola adequado do solo, a monocultura extensiva; estão entre os as ações promotoras da erosão.

As plantas exóticas encontradas na área pertencem ao gênero brachiaria e possuem crescimento bem distribuído em toda área, o que dificulta o crescimento de espécies nativas. A causa da presença do banco de sementes desse tipo de gramínea exótica é devido ao histórico de uso da área. Antes da utilização do espaço como universidade, a área era propriedade rural que possuía área de pastagem. Além disso, as espécies invasoras possuem um banco de sementes bem resistente a diversos tipos de intempéries, fácil adaptação a variados tipos de solos, são pouco exigentes quanto a qualidade física e química do solo, não apresentam 
problemas de doenças e não necessitam de estabilidade ambiental como às espécies nativas (REIS et al., 2015).

O desmatamento para a construção da represa associado a ausência de iniciativas para recompor a área ripária formada após o alagamento da área, causando a exposição da área, foi o ponto de partida dos impactos gerados na área e consequentemente a geração dos processos descritos acima (Figura 4).

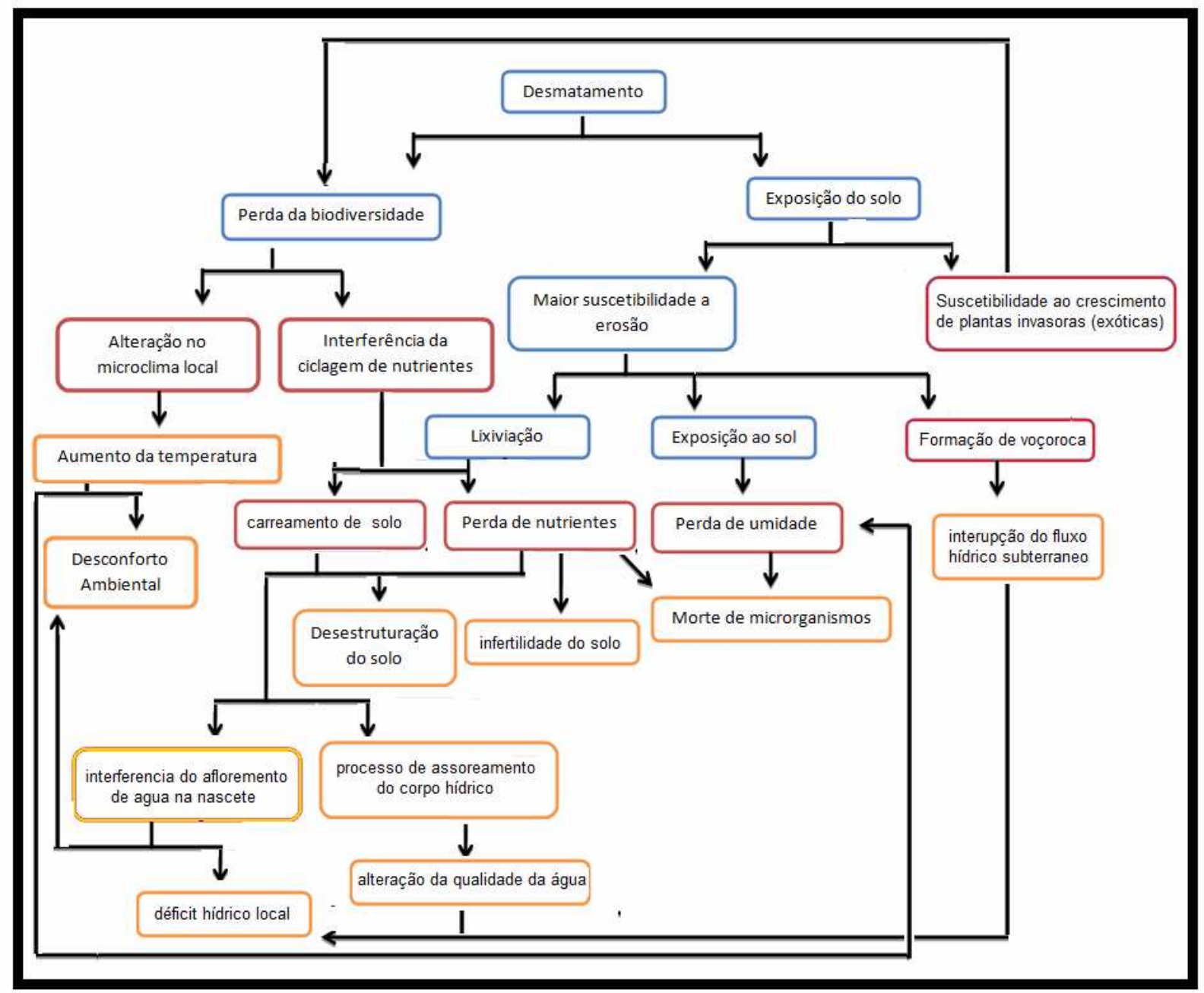

FIGURA 4: Fluxograma dos fatores ambientais diagnosticados na área e os respectivos impactos.

A exposição do solo gera maior susceptibilidade ao crescimento de plantas exóticas e maior susceptibilidade à erosão, o que contribui para a lixiviação do solo, gerando perda de nutrientes e da umidade do solo e por conseguinte a morte dos micro-organismos e infertilidade do solo. Além disso, essa susceptibilidade à erosão cria a possibilidade de formação de voçoroca, podendo gerar interrupção do fluxo hídrico.

A rede de interação possibilitou melhor visualização dos efeitos desencadeados pelas ações geradoras de degradação nos meios físico-quimico, biótico e socioeconômico. Assim, foi possível identificar com mais clareza os impactos ambientais para a análise qualitativa, quantitativa e proposição das medidas mitigatórias. Essa análise foi materializada na matriz de Leopold, adaptada por Sanchez (2008), uma para análise qualitativa (Quadro 2) e outra para análise quantitativa (Quadro 3). 
QUADRO 2: Matriz qualitativa dos impactos.

\begin{tabular}{|c|c|c|c|c|c|c|}
\hline \multirow[b]{2}{*}{ IMPACTOS } & \multicolumn{2}{|c|}{ Meio biótico } & \multicolumn{2}{|c|}{ Meio abiótico } & \multicolumn{2}{|c|}{ Meio socioeconômico } \\
\hline & Fauna & Flora & Água & Solo & $\begin{array}{c}\text { Necessidade } \\
\text { de agua }\end{array}$ & $\begin{array}{c}\text { Conforto } \\
\text { ambiental }\end{array}$ \\
\hline $\begin{array}{c}\text { Perda da } \\
\text { biodiversidade }\end{array}$ & $\begin{array}{l}\text { D, N, P, } \\
\text { IM, R, LO }\end{array}$ & $\begin{array}{l}\text { D, N, P, } \\
\text { IM, R, LO }\end{array}$ & $\begin{array}{c}\text { D, N, P, } \\
\text { CP, R } \\
\text {,RG }\end{array}$ & $\begin{array}{c}\mathrm{D}, \mathrm{N}, \mathrm{P} \\
\mathrm{IM}, \mathrm{R}, \mathrm{LO}\end{array}$ & $\begin{array}{c}\text { I, N, P, MP, } \\
\text { R ,LO }\end{array}$ & $\begin{array}{c}\text { D, N, P, } \\
\text { IM, R, LO }\end{array}$ \\
\hline $\begin{array}{l}\text { Crescimento } \\
\text { de plantas } \\
\text { Exóticas }\end{array}$ & $\begin{array}{l}\text { D, N, P, } \\
\text { CP, R, } \\
\text { LO }\end{array}$ & $\begin{array}{l}\text { D, N, P, } \\
\text { IM, R, LO }\end{array}$ & $\begin{array}{l}\text { D, N, T, } \\
\text { MP, R, } \\
\text { LO }\end{array}$ & $\begin{array}{c}\mathrm{D}, \mathrm{N}, \mathrm{P} \\
\mathrm{CP}, \mathrm{R}, \mathrm{LO}\end{array}$ & $\begin{array}{l}\text { I, N, T, MP, } \\
\text { R, LO }\end{array}$ & $\begin{array}{c}\text { I, N, P, } \\
\text { CP, R, LO }\end{array}$ \\
\hline Erosão do solo & $\begin{array}{l}\text { I, N, P, } \\
\text { LP, R, LO }\end{array}$ & $\begin{array}{l}\text { D, N, P, } \\
\text { IM, R, LO }\end{array}$ & $\begin{array}{l}\text { D, N, T, } \\
\text { CP, R, } \\
\text { RG }\end{array}$ & $\begin{array}{c}\mathrm{D}, \mathrm{N}, \mathrm{T} \\
\mathrm{IM}, \mathrm{R}, \mathrm{LO}\end{array}$ & $\begin{array}{c}\text { I, N, P,CP, } \\
\text { R, RG }\end{array}$ & $\begin{array}{c}\text { I, N, P, } \\
M P, \text { R, LO }\end{array}$ \\
\hline $\begin{array}{l}\text { Alteração da } \\
\text { qualidade da } \\
\text { água }\end{array}$ & $\begin{array}{l}\text { D, N, P, } \\
\text { CP, R, } \\
\text { LO }\end{array}$ & $\begin{array}{l}\text { D, N, P, } \\
\text { CP, R, } \\
\text { LO }\end{array}$ & $\begin{array}{c}\text { D, N, P, } \\
\text { IM, R, } \\
\text { RG }\end{array}$ & $\begin{array}{c}\mathrm{D}, \mathrm{N}, \mathrm{P} \\
\mathrm{IM}, \mathrm{R}, \mathrm{RG}\end{array}$ & $\begin{array}{c}\text { D, N, P, } \\
C P, R, R G\end{array}$ & $\begin{array}{c}\text { I, N, P, } \\
\mathrm{CP}, \mathrm{R}, \mathrm{LO}\end{array}$ \\
\hline
\end{tabular}

Legenda: D: Direta; I: Indireta; N: Negativo; P: Positivo; T: Temporário; PE: Permanente; IM: Imediato; CP: Curto Prazo; MP: Médio Prazo; LP: Longo Prazo; LO: Local; RG: Regional; IR: Irreversível; R: Reversível.

A qualificação denotou que os impactos encontrados não causaram nenhuma influência positiva em nenhum dos meios. A maioria dos impactos encontrados são diretos, ou seja, são notados em curto espaço de tempo após as ações de degradação serem realizadas. Os impactos avaliados na área são considerados reversíveis, ou seja, podem ser eliminados mediante intervenção antrópica e os seus efeitos mitigados. Com base nas informações adquiridas foi realizada a análise quantitativa dos impactos, que é apresentada no quadro 3 abaixo.

QUADRO 3: Matriz de Caracterização Quantitativa

\begin{tabular}{|c|c|c|}
\hline Impactos & Magnitude & Importância \\
\hline Perda da biodiversidade & 7 & $>>$ \\
\hline Crescimento de plantas Exóticas & 5 & $>$ \\
\hline Erosão do solo & 5 & $>$ \\
\hline Alteração qualitativa da água & 7 & $>>$ \\
\hline
\end{tabular}

A perda da biodiversidade e a alteração da qualidade da água exercem maior grau de influência na área, o que gera efeitos mais significativos na qualidade ambiental local. Além disso, esses impactos demostram ter maiores efeitos em todos os compartimentos analisados, por possuírem maior magnitude e importância em relação aos outros impactos (quadro 3).

Diante dos dados coletados e dos impactos analisados observou-se que a área necessita de intervenção, de ações que reparem os danos causados e reabilitem a área. As intervenções resultaram em medidas mitigadoras corretivas, que constitui em recompor a situação anterior aos processos degradantes sobre os meios através de ações de eliminação dos fatores geradores do impacto (MARTINS, 2013).

Após a análise de dados, verificou-se que as medidas mitigadoras necessárias para a restauração da área são:

1. Supressão da vegetação exótica; 
2. Manejo do solo;

3. Revegetação da área.

Algumas metodologias para revegetação de área degradada são baseadas no modelo de plantio sucessional. Este baseia-se na premissa de que a introdução de espécies tolerantes a sombra (pioneiras) crescem e geram sombra, criando um microssítio favorável, desenvolvimento de um sub-bosque formado por espécies mais tolerante a sombra (não pioneiras), que as substituirão após a senescência ao longo do tempo. Nesse modelo, o plantio de pioneiras e de não pioneiras pode ser realizado simultaneamente ou em diferentes épocas; através de semeadura direta ou pelo plantio de mudas.

O sucesso do modelo sucessional vem da efetiva proteção do solo contra processos de erosão e consequentemente do curso d'água, evitando o assoreamento. Além disso, o plantio sucessional congrega a recuperação de fatores indispensáveis para a sustentabilidade de espécies, a ciclagem de nutrientes, a atração e manutenção da fauna etc (MARTINS, 2013).

Outra vantagem deste modelo com o plantio de pioneiras é que o solo formará acúmulo de serapilheira e húmus, ambiente propício para receber a chuva de sementes que chegará por dispersão, favorecendo a germinação e o desenvolvimento de espécies e dará início ao processo de sucessão vegetal que culminará na restauração da área degradada após um certo tempo (MARTINS, 2013).

O estudo de Barbosa (2002) confirmou que este modelo sucessional favorece a rápida cobertura do solo e garante a auto-renovação da floresta. Fontana e Bündchen (2015) observaram que através da aplicação do modelo sucessional, a regeneração natural teve aumento significativo na riqueza de plantas.

Conforme Martins (2013) é importante que sejam plantadas espécies pioneiras nativas da região, pois o plantio de nativas de outros locais, mesmo que pertencentes ao mesmo país, pode ter como consequência vários impactos negativos, entre estes a formação de floresta com baixa capacidade de se autosustentar.

\section{CONCLUSÃO}

- A área de estudo localizada na Universidade foi degradada devido a construção da represa.

- $\quad$ Foram observados impactos significativos na área, porém passíveis de serem recuperados.

- Os impactos com maior magnitude e importância observados foram perda da biodiversidade e alteração da qualidade da água.

- $\quad$ As medidas corretivas indicadas para a restauração da área são: supressão da vegetação exótica, manejo do solo revegetação da área através do modelo sucessional.

\section{REFERÊNCIAS}

ARAÚJO, G.H.S., ALMEIDA, J.R.; GUERRA, A.J.T. Gestão Ambiental de Áreas Degradadas. Rio de Janeiro, Editora Bertrand Brasil, 4ae edição. 2010.

AMBIENTE BRASIL. Recuperação de mata ciliar. 2015. Disponível em: $<$ http://ambientes.ambientebrasil.com.br/florestal/recuperacao_de_matas_ciliares/rec uperacao_de_matas_ciliares.html>. Acesso em: 17 de agosto de 2015. 
BARBOSA, L.M. Considerações gerais e modelos de recuperação de formações ciliares. In Matas Ciliares: conservação e recuperação (R.R. Rodrigues e H.F. Leitão Filho, eds.) Edusp, São Paulo, p.289-311, 2002.

BRASIL- Lei $\mathbf{n}^{\circ}$ 12.651 de maio de 2012. Código Florestal Brasileiro Disponível em: <http://www.planalto.gov.br/ccivil_03/_ato2011- 2014/2012/lei//12651.htm> Acesso em: 02 set. 2015.

BRASIL- Resolução Conama no 001, de 23 de janeiro de 1986. Disponível em: < http://www.mma.gov.br/port/conama/res/res86/res0186.html> Acesso em: 02 set. 2015

CREMONEZ, F. E.; CREMONEZ, P. A.; FEROLDI, M.; CAMARGO, M. P. de; KLAJN, F. F.; FEIDEN, A. Avaliação de impacto ambiental: metodologias aplicadas no brasil. Revista Monografias Ambientais, [s.I.], v. 13, n. 5, p.3821-3830, 16 nov. 2014. Universidade Federal de Santa Maria. http://dx.doi.org/10.5902/2236130814689. Disponível em: <file:///C:/Users/b/Downloads/14689-74080-1-PB (3).pdf>. Acesso em: 01 fev. 2016.

FONTANA, C.; BÜNDCHEN, M. Restoration of riparian vegetation on a small farm. Ambiência, [s.l.], v. 11, n. 1, p.149-162, jan. 2015. GN1 Genesis Network. http://dx.doi.org/10.5935/ambiencia.2015.01.09. Disponível em: $<$ http://revistas.unicentro.br/index.php/ambiencia/article/viewFile/2430/2555>. Acesso em: 04 abr. 2016

FRANCO, J. L. de A. O conceito de biodiversidade e a história da biologia da conservação: da preservação da wilderness à conservação da biodiversidade. História (são Paulo), [s.l.], v. 32, n. 2, p.21-48, dez. 2013. FapUNIFESP (SciELO). http://dx.doi.org/10.1590/s0101-90742013000200003. Disponível em: <http://www.scielo.br/pdf/his/v32n2/a03v32n2.pdf>. Acesso em: 12 dez. 2016.

IBAM, Instituto Brasileiro de Administração Municipal. Guia Prático para Elaboração de Projeto de Recuperação de Áreas Degradadas (PRAD) em APP. Nota Técnica n.. 03. 2015. Disponível em: <http://www.amazoniaibam.org.br/images/pqga/arquivos/003_prad.pdf. >. Acesso em: 20 fev. 2016

MARTINS, S. V. Recuperação de áreas degradadas: Ações em áreas de preservação permanente, voçorocas, taludes rodoviários e de mineração. 3. ed. Viçosa, Mg: Aprenda Fácil, 2013. 264 p.

NERES, N. G. C.; SOUZA, P. A. de; BENDITO, B. P. C.; GONÇALVES, D. S.; SANTOS, A. F. dos. Avaliação ambiental e indicação de medidas mitigadoras para a nascente do córrego mutuca, Gurupi-TO. Enciclopédia Biosfera: Centro Científico Conhecer, Goiânia, v. 21, n. 11, p.2824-2834, 01 jun. 2015. Disponível em: $<$ http://www.conhecer.org.br/enciclop/2015c/agrarias/proposta\%20de\%20recuperaca o.pdf>. Acesso em: 20 fev. 2016 
PAULA, M. B.; GOMES, A. de C.; NATAL, D.; DUARTE, A. M. R. de C.; MUCCI, L. F. Effects of Artificial Flooding for Hydroelectric Development on the Population ofMansonia humeralis(Diptera: Culicidae) in the Paraná River, São Paulo, Brazil. Journal of Tropical Medicine, [s.I.], v. 2012, n. 2012, p.1-6, 2012. Hindawi Publishing Corporation. http://dx.doi.org/10.1155/2012/598789. Disponível em: <https://www.ncbi.nlm.nih.gov/pmc/articles/PMC3317009/>. Acesso em: 20 dez. 2016.

REIS, A. da S.; SOUZA, P. A. de; SANTOS, A. F. dos; GIONGO, M.; NERES, N. G. C. Impactos ambientais diagnosticados na nascente do córrego san rival: Fazenda Meu Paraiso, Palmeirópolis-Tocantins. Enciclopédia Biosfera: Centro Científico Conhecer, Goiânia, v. 11, n. 21, p.3166-3184, 01 jun. 2015. Disponível em: <http://www.conhecer.org.br/enciclop/2015b/multidisciplinar/impactos\%20ambientais. pdf>. Acesso em: 20 fev. 2016.

ROCHA, R. P.; MAIA, E. L.; VIEIRA, S. de S.; LEITE, E. M. Diagnóstico sócioambiental da nascente da comunidade do cocal em palmeira do Piauí PI. Educação Ambiental em Ação, Novo Hamburgo, Rs, v. /, n. 50, p.1-10, dez. 2014. Disponível em: <http://revistaea.org/artigo.php?idartigo=1909>. Acesso em: 20 dez. 2016.

SARI, V.; POLETO, C.; CASTRO, N. M. dos R. Caracterização dos processos hidrossedimentológicos em bacias rurais e urbanas. Enciclopédia Biosfera, Centro Científico Conhecer, Goiânia, v. 9, n. 16, p.596-624, jan. 2013. Disponível em: <http://www.conhecer.org.br/enciclop/2013a/agrarias/caracterizacao dos processos.pdf>. Acesso em: 25 maio 2016.

SEPLAN - Secretaria do Planejamento. Superintendência de Planejamento e Gestão Central de Políticas Públicas. Diretoria de Zoneamento Ecológico-Econômico (DZE). Base de Dados Geográficos do Tocantins. Versão 2012. Palmas, Seplan/DZE, 2009. DVD-ROM. (Dados vetoriais temáticos estruturados em escalas 1:250.000, 1:500.000 e 1:1. 000.000). Disponível em: < www.seplan.to.gov.br.>. Acesso em: 25 maio 2016

SÁNCHEZ, L. E. Avaliação de impacto ambiental: conceitos e métodos. São Paulo: Oficina de Textos, 2008. 495p. 